
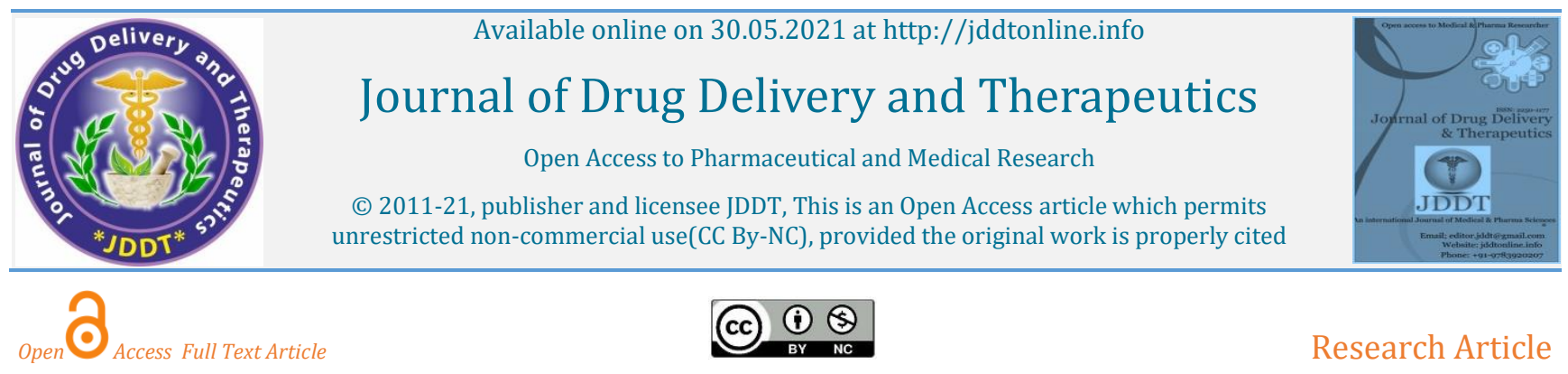

Research Article

\title{
Description of Triglyceride Risk Factors with Ischemic Stroke Patients at UKI Hospital for 2018
}

\author{
Ganda Pariama1*, Agus Yudawijaya ${ }^{1.2}$ \\ ${ }^{1}$ Faculty of Medicine, Universitas Kristen Indonesia, Jakarta, Indonesia \\ 2 SMF Neurologi RSU UKI, Jakarta, Indonesia
}

Article Info
Received 26 March 2021
Acviewed 14 May 2021
Published 30 May 2021

Abstract

Stroke is a neurologic disease that results from a blood supply to the brain. Ischemic stroke is the most frequent stroke caused by thrombus and embolism. Stroke patients in urban areas, roughly $28,5 \%$ die, the rest are either completely paralyzed or even totally paralyzed, and the rest $15 \%$ healed. Riskesdas' 2018 data, the rate of strokes at age 75 reaches $50,2 \%$ and the male gender with an $11 \%$ while women are $10,9 \%$. One of the minor risk factors that can be controlled is high blood fat, triglycerides. That study was conducted to assess the risk factor for record triglycerides with ischemic stroke patients at the General Hospital of the Christian University of Indonesia. The study uses a retrospective descriptive method-data retrieval using medical records. Taking samples using is a total sampling method from January - December 2018 with 113 patients. Triglycerides above normal are 63 patients $(55,8 \%)$, high cholesterol total and LowDensity Lipoprotein levels is 68 patients $(60,2 \%)$ and 61 patients (54 \%). Male patients has $59(52,2 \%)$.

Keyword: Ischemic stroke, Triglycerides

\section{INTRODUCTION}

Stroke is still the second highest cause of death after heart disease and is one of the causes of the highest disability rate in the world. In the Association of Southeast Asian Nations (ASEAN) countries, stroke is also a significant health problem that can cause death. In Indonesia, stroke accounts for $15.4 \%$ of all deaths. Apart from being the leading cause of death, stroke is also the leading cause of disability in Indonesia. Stroke, also known as cerebrovascular disease, is a neurological disease that occurs due to disruption of blood supply to the brain. ${ }^{1}$ There are two types of stroke, namely ischemic stroke and hemorrhagic stroke. Ischemic strokes are caused due to thrombotic or embolic obstruction, and these strokes occur most often, while hemorrhagic strokes are caused by bleeding due to the rupture of a blood vessel in a part of the brain. Disability due to stroke affects the person and their family.,2,3

The trigger factors that cause stroke include age. The older a person will increase the risk of having a stroke because the older a person, the nervous system decreases in function. ${ }^{4}$ Gender factors, men are more at risk than women because men have a habit of smoking and drinking alcohol which are risk factors for stroke, while in women, the risk of having a stroke increases after menopause. Family history factors, people who have offspring with a history of stroke will increase the risk of having a stroke. ${ }^{1}$ Obesity factor, obesity is closely related to cholesterol levels in the blood, which causes an increase in high LDL cholesterol (low- density lipoprotein) and low HDL (high-density lipoprotein). It can increase the risk of stroke, and when coupled with factors triggers such as smoking, drinking alcohol and hypertension, it will increase the risk factors for stroke. Saturated fats are fatty acids that do not have double bonds on carbon atoms. Foods that contain saturated fats such as foods derived from animal meat, dairy products, cheese, butter and processed foods. The dominant effect of saturated fatty acids is an increase in total and LDL cholesterol levels. Unsaturated fats are fatty acids that have the chemical structure of one or more double chain bonds. Foods that contain unsaturated fats such as olive oil, soybean oil, corn, nuts and seeds. Saturated and unsaturated fats are part of the fat that is often consumed daily. The lipid profile (blood fat content) consists of total cholesterol, LDL, HDL and triglycerides. 3,5

Dyslipidemia is a lipid metabolism disorder that can be in the form of an increase or decrease in the lipid fraction, including an increase in cholesterol levels, an increase in triglyceride levels, an increase in LDL levels and a decrease in HDL levels. According to research published in 2016, Novy stated that abnormalities caused atherosclerosis and embolus formation in the lipid profile in blood plasma, leading to ischemic stroke. In contrast, there was no significant difference in triglyceride levels in ischemic stroke patients. ${ }^{5}$

Based on the description above, as a researcher, I am interested in researching the description of triglyceride risk 
factors with ischemic stroke patients at the UKI General Hospital. Thus, the problem in this study is formulated as follows "What is the Description of Triglyceride Risk Factors with Ischemic Stroke Patients at the UKI General Hospital for the period 2018?" to know the risk factors for triglycerides with ischemic stroke patients at the General Hospital of the Christian University of Indonesia, Jakarta in the period 2018.

\section{THEORETICAL REVIEW}

Anatomy and Physiology of the Brain - The brain is located in the cranium, consisting of the central nervous system (CNS) part above the spinal cord. Anatomically it consists of the cerebrum (cerebellum), cerebellum (cerebellum), brainstem (brain stem) and limbic system (limbic system). ${ }^{6}$ The human brain is the most metabolically active organ. Although it weighs only $2 \%$ of body weight, the brain receives $70 \%$ of the body's glucose and uses $25 \%$ of the oxygen needed by the human body to carry out its metabolism. ${ }^{7}$ The brain is a vital organ consisting of 100-200 billion active cells interconnected and responsible for mental and intellectual functions. The cells in the brain are also called neurons. The nervous system in the brain is divided into two parts, namely the central nervous system (CNS) and the peripheral nervous system (CNS). The central nervous system is formed by the brain and spinal cord, while the peripheral nervous system is the nervous system on the outer side of the CNS. The function of the SST itself is to deliver information between the CNS and other parts of the body, and vice versa. ${ }^{8}$

The brain components are a) Cerebrum - the cerebrum, which consists of a pair of right and left hemispheres and is composed of the cortex. The cortex is characterized by sulcus (fissure) and gyrus (protruding part of the lobe); 6 b) Cerebellum - cerebellum, which contains more neurons than the brain as a whole. It has an important coordination role in motor function based on the received somatosensory information. The cerebellum is the coordination centre for balance and muscle tone, such as regulating posture and body position; c) Brainstem functions to regulate all basic life processes. They are associated with the diencephalon above and the spinal cord underneath; d) Limbic system: located in the middle of the brain, which functions as a regulator of human emotions, expression of instinctual behaviour, and part of the brain most sensitive to stimuli. ${ }^{6}$

The cerebrum is divided into four lobes, namely: ${ }^{8}$ a) Frontal lobe - This lobe is divided into three main components, namely the primary motor cortex (area 4), the premotor cortex (area 6) and the prefrontal cortex; b) Parietal lobe - This lobe is the central area of sensory awareness in the postcentral gyrus (primary sensory area) for the sense of touch and hearing; c) Temporal lobe - This lobe acts as a centre for hearing, understanding language (Wernicke), understanding sound and musical rhythm and regulating memory functions; and d) The occipital lobe - This lobe acts as a centre for receiving and analyzing vision of the optic nerve, and also for recognizing vision and colour.

Blood flow to the brain is carried out by the two main arteries, namely by a pair of internal carotid arteries and vertebral arteries. These four arteries are located within the subarachnoid space and their branches anatomy on the inferior surface of the brain to form the circulus of Willis. The internal carotid artery, basilar artery, anterior cerebral artery, 12 anterior communicating arteries, posterior cerebral artery, posterior communicating artery and basilar artery contribute to this circulus. ${ }^{7}$ Loss of consciousness occurs when blood flow to the brain stops 15 seconds or less, and permanent brain tissue damage occurs when blood flow to the brain stops within 5 minutes. Cerebrovascular disease or stroke occurs due to vascular disorders or bleeding and is the most common cause of neurological disability. ${ }^{8}$

Ischemic Stroke - Stroke is a cerebrovascular (brain blood vessel) disease characterized by impaired brain function due to damage or death of brain tissue due to reduced or obstructed flow of blood and oxygen to the brain. ${ }^{9}$ According to WHO (World Health Organization), stroke is a clinical manifestation of cerebral dysfunction, both local and comprehensive (global), takes place quickly, more than 24 hours or ends in death, without finding a cause other than vascular disorders. If not handled properly, it will result in disability. Stroke is divided into two types: hemorrhagic stroke, an acute focal neurological dysfunction and is caused by primary bleeding of brain substances that occurs spontaneously, not due to capitis trauma but caused by the rupture of arteries, veins and capillaries and ischemic stroke. Non-hemorrhagic stroke is the death of brain tissue due to impaired blood flow to brain areas caused by blockage of the cerebral arteries or cerebral veins. ${ }^{10}$

Hemorrhagic stroke or bleeding stroke is divided into two, namely intracerebral haemorrhage, primary bleeding originating from blood vessels in the brain's parenchyma. It can cause brain performance to stop, the most common cause is hypertension, and subarachnoid haemorrhage is a rupture of blood vessels that causes blood to enter the subarachnoid space. The cause can be varies but is usually due to aneurysm rupture. 9,11

Ischemic stroke or blockage stroke is divided into two, and namely thrombotic stroke is a stroke caused by a blockage in the lumen of the brain blood vessels because the thrombus is getting thicker, so that blood flow is not smooth. This decrease in blood flow causes ischemia, and an embolic stroke is a blood clot or Plaque that builds up in the heart of atheromatous lesions located in the more distal arteries. When the embolus reaches a too narrow artery to pass and becomes blocked, the distal fragment blood flow stops, resulting in infarction of distal brain tissue due to a lack of nutrients and oxygen. 9,11

Epidemiology of ischemic stroke - Stroke is a noncommunicable disease (PTM) that can cause death and ranks second after heart disease according to WHO in 2015. Stroke patients in urban areas, about $28.5 \%$ die, the rest are paralyzed or even completely paralyzed, and the rest $15 \%$ can recover. ${ }^{11}$ Data from Riskesdas 2007, stated that the prevalence of stroke in Indonesia was 8.3 per 1000 population, while in Riskesdas 2013, the prevalence of stroke based on diagnosis by health professionals and symptoms was the highest in South Sulawesi (17.9\%), DI Yogyakarta (16.9\%), Central Sulawesi. (16.6\%), followed by East Java at (16\%). According to Riskesdas 2018 data, the prevalence of stroke in Indonesia is $10.9 \%$. At the age of 75 years and over, the prevalence of suffering from stroke reaches $50.2 \%$ and the gender is male (11\%) and female $(10.9 \%)$. The population living in urban areas $(12.6 \%)$ is higher than those living in rural areas (8.8\%).12

Aetiology of ischemic stroke - Ischemic stroke can be caused by extracranial embolism or intracranial thrombosis but can also be caused by reduced blood flow to the brain. One of the causes, namely: a) Atherosclerosis, is the accumulation of fat in the inner lining of blood vessels. If the fat has covered the entire lumen of the blood vessels, blood flow will be blocked. b) Embolism is blockage of brain blood vessels by blood clots or air bubbles. In general, embolism originates from a thrombus in the heart that detaches and 
blocks the cerebral artery system. The embolism was rapid, and symptoms lasted less than 10-30 seconds. Several conditions can cause embolism in the event of myocardial infarction, fibrillation, which is an arrhythmia that causes various forms of ventricular emptying so that the blood forms small clots. It can empty at any time by releasing a small embolus and can also be due to endocarditis which causes clots to form in the endocardium; ${ }^{13}$ and c) lacunar infarction, is a clinical stroke syndrome with specific symptoms and signs, which are small lesions in the subcortex or brainstem. The size of the lacunar infarction is thought to be related to the size of the affected artery because larger lesions are more likely to cause symptoms. Symptomatic lacunar infarction is believed to be associated with atherosclerosis or embolism of the larger arteries. ${ }^{14,15}$

Ischemic stroke can be caused by atherosclerosis, a thrombotic mechanism that blocks large arteries and small arteries or due to the embolic mechanism. Impaired cerebral blood supply can occur anywhere within the arteries that make up the Circulus of Willis. The presence of a thrombus or blockage in the brain will decrease blood flow to part of the brain so that oxygen in the brain decreases. As a result, there is deprivation of neurons from oxygen and glucose. If not treated promptly, the state of oxygen deficiency in the brain will result in disruption of cellular processes, which results in cell death in the brain. ${ }^{10,16}$ Cell death in the brain is referred to as an infarction. The part of the brain that experiences infarction will certainly experience interference with neuronal processes. The neurons will stop functioning so that the patient will experience disturbances in his body function according to the location of the brain that has the infarction. If the part affected is the internal capsule, there will be paralysis or weakness in one or both sides of the body. The location of the internal capsule is in the cerebrum, located between the lentiform nucleus and the caudate and thalamus nuclei. There are branches of the internal carotid artery, namely the middle cerebral artery and the anterior cerebral artery. If there is a blockage in the artery branching, it will obstruct blood flow, resulting in various symptoms such as stroke. This decrease in motor function in stroke patients will result in limitations in range of motion and mobilization. This mobility includes the ability to mobilize in bed, walk, or move places. ${ }^{17}$

Clinical symptoms of ischemic stroke - Symptoms and signs of stroke vary widely, depending on the part of the brain affected. However, in general, the signs and symptoms that are often encountered include.11: a) There is a tingling feeling in the whole body or numbness and usually loses the balance of the body; b) Limp or even paralysis in the half of the body, right or left only; c) The mouth and tongue are inclined when straightened; d) Impaired swallowing, or if you drink frequently choking; e) Speech disorders, in the form of pelo or accentuation of difficult words to understand. Even speech is not fluent, only a few words; f) Not able to read and write. Sometimes it begins with an unusual change in writing, and the writing is worse; g) Walking becomes complicated with only small steps; h) Less able to understand other people's speech; i) Intellectual ability has decreased drastically, and j) Impaired sensory function so that vision problems can occur.

Triglycerides - The levels of triglycerides are stored in fat cells in the body. Triglycerides are composed of $90 \%$ fat in food. The body needs triglycerides for energy. Lipoproteins are compounds that carry triglycerides and other fats to be circulated throughout the body. Triglycerides in the blood are transported through two routes, namely the exogenous route and the endogenous route. In the exogenous pathway, the triglycerides in the intestine are packaged in chylomicrons, which will undergo further breakdown carried out by the lipoprotein lipase enzyme so that free fatty acids and remnant chylomicrons are formed. The free fatty acids produced will move through the muscle tissue and fat tissue under the skin, then in that tissue, the fatty acids are converted back into triglycerides which function as energy reserves while the remnant chylomicrons go to the liver. In the endogenous pathway, triglycerides are transported in lipoprotein called Very Low-Density Lipoprotein (VLDL). The enzyme lipoprotein lipase will hydrolyze triglycerides outside the liver and in the tissue. The rest of the hydrolysis is then metabolized by the liver to LDL cholesterol. High triglyceride levels often have high levels of LDL cholesterol and low HDL cholesterol. Increased triglyceride levels also make LDL cholesterol toxic to artery walls and reduce the beneficial effects of HDL. People who are overweight or obese often also have triglyceride levels that exceed normal limits. These conditions will increase the risk of suffering from heart disease or stroke. ${ }^{18}$

High cholesterol levels are a modifiable risk factor for atherosclerosis, which is the fundamental pathology in ischemic stroke. The function of total cholesterol is to strengthen and stabilize the walls of blood vessels, especially when the walls of blood vessels require greater strength to withstand high blood pressure. In addition, high cholesterol levels significantly increase the risk of death from coronary artery disease, myocardial, pulmonary and cerebral infarction. Cholesterol is divided into two, namely LDL and HDL cholesterol. ${ }^{19}$

One of the serum cholesterols is LDL which is the primary carrier of cholesterol in humans and is responsible for supplying cholesterol to all body tissues to fulfil the need for cholesterol. LDL cholesterol is also a lipoprotein that is involved in the formation of atherogenic plaques. Circulating LDL levels may be increased in people who consume large amounts of saturated fat or cholesterol. LDL can cause atherosclerosis by oxidizing LDL in the subendothelial lining of the artery, causing an inflammatory reaction which in turn narrows the blood vessels called atherosclerosis. Atherosclerosis will occur when a blockage in the carotid artery or artery leading to the brain can cause blockage (ischemic stroke). A meta-analysis of statin trials showed that the more significant the reduction in LDL cholesterol levels, the greater the reduction in stroke risk. HDL cholesterol is the only anti-thrombotic lipoprotein, so low HDL cholesterol levels are associated as a risk factor for atherosclerosis in ischemic stroke. However, ischemic stroke has multiple or multifactorial risk factors not only associated with atherosclerosis due to abnormal lipid profile levels or dyslipidemia. ${ }^{20,21}$

\section{RESEARCH METHOD}

The type of research used in this research is observational with a descriptive and retrospective crosssectional method, where the data collected is based on past data, namely the researcher will look at the medical records of patients with a history of ischemic stroke, and there are laboratory results of triglyceride tests at the UKI Hospital for the period 2018. Data collection was carried out in October November 2019 at the medical records section of the General Hospital of the Christian University of Indonesia. The study population was all data on ischemic stroke patients at the General Hospital of the Christian University of Indonesia for the period 2018 with 125 people. The total sample used was all populations that met the inclusion criteria, namely 113 people. All secondary data that has been collected will be 
grouped and then processed with SPSS version 16 software. The data analysis used in univariate analysis. Univariate analysis is used to describe the distribution and frequency of the observed variables. In this study, the univariate analysis aims to describe the risk factors for triglycerides in ischemic stroke patients at UKI Hospital.

\section{RESULT AND DISCUSSION}

This research was conducted in the medical record unit of the UKI Hospital by taking secondary data from ischemic stroke patients at the UKI Hospital in the period 1 January - 31 December 2018. The research conducted with the total sampling method where the entire population who entered the inclusion criteria would be the study sample. The research results can be seen below:

Table 1: Description of ischemic stroke patient data based on triglyceride risk factors

\begin{tabular}{ccc}
\hline Trigliserida & Frequency (n) & $\%$ \\
\hline$<150$ & 50 & 44.2 \\
$>150$ & 63 & 55.8 \\
\hline Total & 113 & 100.0
\end{tabular}

Based on the description of the table above, it was found that 63 patients (55.8\%) had an ischemic stroke with elevated triglyceride levels, while 50 patients (44.2\%) had low triglyceride levels or at normal limits.

Table 2: Description of ischemic stroke patient data based on risk factors for total cholesterol

\begin{tabular}{ccc}
\hline Total Kolesterol & Frequency (n) & $\%$ \\
\hline$<200$ & 45 & 39.8 \\
$>200$ & 68 & 60.2 \\
\hline Total & 113 & 100.0
\end{tabular}

Based on the description of the table above, it was found that there were 68 patients with ischemic stroke with an increase in total cholesterol levels $(60.2 \%)$, while 45 patients $(39.8 \%)$ of ischemic stroke patients had total cholesterol levels within normal or low limits.

Table 3: Data description of ischemic stroke patients based on risk factors for LDL (low-density lipoprotein)

\begin{tabular}{ccc}
\hline LDL & Frequency (n) & $\%$ \\
\hline$<155$ & 52 & 46.0 \\
$>155$ & 61 & 54.0 \\
\hline Total & 113 & 100.0
\end{tabular}

Based on the description of the table above, it was found that there were 61 patients $(54 \%)$ of ischemic stroke patients with increased LDL levels, while 52 patients (46\%) had an ischemic stroke.

Table 4: Description of ischemic stroke patient data based on risk factors for gender

\begin{tabular}{ccc}
\hline Gender & Frequency (n) & $\%$ \\
\hline male & 59 & 52.2 \\
female & 54 & 47.8 \\
\hline Total & 113 & 100.0
\end{tabular}

Based on the description of the table above, it was found that 59 patients $(52.2 \%)$ had ischemic stroke patients $(52.2 \%)$ while the female gender was 54 patients (47.8\%).
This research is a descriptive study conducted with a cross-sectional retrospective method. Based on the medical record data of ischemic stroke patients at the UKI Hospital in 2018, 113 medical records met the research criteria.

Data overview of ischemic stroke patients based on triglyceride risk factors - The results showed that 63 patients with high triglyceride levels at UKI Hospital with low or normal triglyceride levels were 50 patients with a percentage of $44.2 \%$. It is in line with research published by Nuartha that high triglyceride levels amounted to 23 people with a percentage of $63.9 \%$, and normal triglyceride levels amounted to 7 people with a percentage of $19.4 \% .^{22}$ However, this is not in line with the research conducted by Pratiwi which states that the average triglyceride level in ischemic stroke patients is $143 \mathrm{mg} / \mathrm{dl}$, which is $<150 \mathrm{mg} / \mathrm{dl}$. 24]. Triglyceride ratio level is a routine examination for acute ischemic stroke patients to detect small dense LDL, which plays a role in showing the degree of stroke severity and prognosis of acute stroke patients. ${ }^{23}$ High triglyceride levels have high atherogenicity properties that play a role in the progression of atherosclerosis. ${ }^{24}$ Atherosclerosis affecting the large and medium arteries in the neck and head can cause an ischemic stroke. Patients with high triglyceride levels had a twofold greater risk than those with normal triglyceride levels. ${ }^{25}$

Description of ischemic stroke patient data based on risk factors for total cholesterol - The results showed that there were 68 patients with ischemic stroke at UKI Hospital with total cholesterol levels more than normal with a percentage of $60.2 \%$ and 45 patients with total cholesterol levels within normal or low limits. with a percentage of $39.8 \%$. It is in line with research conducted by Zulhafis that total cholesterol levels increased by 78 patients with a percentage of $62.4 \%$ and an average total cholesterol level of 47 patients with a percentage of $37.6 \% .^{26}$ It is also in line with research conducted by Amaliah stated that total cholesterol levels increased by 34 patients with a percentage of $63 \%$ and average total cholesterol levels were 20 patients with a percentage of $37 \% .27,28$ Increased total cholesterol levels are one of the factors that trigger atherosclerosis, which can cause blockages in arteries to cause ischemic strokes. ${ }^{29}$

Data description of ischemic stroke patients based on risk factors for LDL (low-density lipoprotein) - The results showed ischemic stroke patients at UKI Hospital in 2018 who had high LDL levels were 61 patients with a percentage of $54 \%$, and low LDL levels totalled 52 patients with a percentage of $46 \%$. It is in line with research conducted by zulhafis that high LDL levels amounted to 72 patients with a percentage of $57.6 \%$ and a low LDL level of 53 patients with a percentage of $42.4 \%$. It is also in line with research conducted by Reski Amaliah et al. at home. Sakit Ibnu Sina, Makassar that increased LDL levels were 31 patients with a percentage of $57 \%$ and normal LDL levels were 23 patients with a percentage of $43 \%$. Excessive LDL levels in the blood can trigger the development of atherosclerosis. Arteries that experience atherosclerosis will lose some of their distensibility, and the area of the blood vessel walls will degenerate, which causes the blood vessels to tear easily. As a result, tissue discontinuity occurs in surrounding structures, including blood vessels in the brain, which can cause narrowing or blockage and tissue ischemia. ${ }^{30}$

Data description of ischemic stroke patients based on gender risk factors - The results showed that male ischemic stroke patients at UKI Hospital were 59 patients with a $52.2 \%$ and 54 women percentage with a percentage of $47.8 \%$. It is in line with research conducted by zulhafis that 
there were 127 male stroke patients with a percentage of $50.8 \%$ and 123 women with a percentage of $49.2 \%$. It is also in line with a study published in 2016 by Amelia and Maulina which stated that 62 patients with ischemic stroke were male with $63.3 \%$ and women with 36 patients. the percentage was $36.7 \% .^{31,32}$ Stroke affects more men than women. In theory, it is stated that women have the hormone estrogen, which functions to regulate collagen in the tunica media and regulate the integrity and thickness of blood vessels so that this hormone can reduce the risk of atherosclerosis. The hormone estrogen can also increase HDL cholesterol levels and reduce LDL cholesterol levels. High HDL cholesterol levels can help clear plaques that stick to the blood, while high levels of LDL cholesterol can cause Plaque in the blood. ${ }^{33}$ After menopause, this protective factor disappears, and the incidence is almost the same as in men.

\section{CONCLUSION}

Based on the results of research conducted at the UKI General Hospital, it can be concluded that an increase follows the increase in triglyceride levels in total cholesterol levels. It is evidenced that $55.8 \%$ of ischemic stroke patients have triglyceride levels above normal from a total sample of 113 people and total cholesterol levels with a percentage of $60.2 \%$. The increase in LDL levels in patients amounted to $54 \%$ of the total sample. In addition, patients with male gender were higher than women with a percentage of $52.2 \%$. Thus, it is advisable to improve the completeness of data and clarity in writing patient medical records so that further researchers can easily read and the data becomes more accurate to support further research.

\section{REFERENCES}

1. Hu X, De Silva TM, Chen J, Faraci FM. Cerebral vascular disease and neurovascular injury in ischemic stroke. Circulation research. 2017 Feb 3; 120(3):449-71. https://doi.org/10.1161/CIRCRESAHA.116.308427

2. Grawburg M, Howe T, Worrall L, Scarinci N. Third-party disability in family members of people with aphasia: A systematic review. Disability and rehabilitation. 2013 Aug 1; 35(16):1324-41. https://doi.org/10.3109/09638288.2012.735341

3. Wan-Fei K, Hassan ST, Sann LM, Ismail SI, Raman RA, Ibrahim F. Depression, anxiety and quality of life in stroke survivors and their family caregivers: A pilot study using an actor/partner interdependence model. Electronic physician. 2017 Aug;9(8):4924. https://doi.org/10.19082/4924 4. Chen RL, Balami JS, Esiri MM, Chen LK, Buchan AM. Ischemic stroke in the elderly: an overview of evidence. Nature Reviews Neurology. 2010 May; 6(5):256-65. https://doi.org/10.1038/nrneurol.2010.36

5. Langsted A, Nordestgaard BG. Nonfasting versus fasting lipid profile for cardiovascular risk prediction. Pathology. 2019 Feb 1; 51(2):131-41. https://doi.org/10.1016/j.pathol.2018.09.062

6. Munshi A, Babu MS, Kaul S, Rajeshwar K, Balakrishna N, Jyothy A. Association of LPL gene variant and LDL, HDL, VLDL cholesterol and triglyceride levels with ischemic stroke and its subtypes. Journal of the neurological sciences. 2012 Jul 15; 318(1-2):51-4. https://doi.org/10.1016/j.jns.2012.04.006

7. Rajagopalan A, Jinu KV, Sailesh KS, Mishra S, Reddy UK, Mukkadan JK. Understanding the links between vestibular and limbic systems regulating emotions. Journal of natural science, biology, and medicine. 2017 Jan; 8(1):11. https://doi.org/10.4103/09769668.198350

8. Pontzer H, Brown MH, Raichlen DA, Dunsworth H, Hare B, Walker K, Luke A, Dugas LR, Durazo-Arvizu R, Schoeller D, Plange-Rhule J. Metabolic acceleration and the evolution of human brain size and life history. Nature. 2016 May; 533(7603):390-2. https://doi.org/10.1038/nature17654
9. Venkat P, Chopp M, Chen J. Blood-brain barrier disruption, vascular impairment, and ischemia/reperfusion damage in diabetic stroke. Journal of the American Heart Association. 2017 Nov 6; 6(6):e005819.

https://doi.org/10.1161/JAHA.117.005819

10. Shuaib A, Butcher K, Mohammad AA, Saqqur M, Liebeskind DS. Collateral blood vessels in acute ischaemic stroke: a potential therapeutic target. The Lancet Neurology. 2011 Oct 1; 10(10):909-21. https://doi.org/10.1016/S14744422(11)70195-8

11. Pahlavan PS, Niroomand F. Coronary artery aneurysm: a review. Clinical cardiology. 2006 Oct; 29(10):439-43. https://doi.org/10.1002/clc.4960291005

12. Pampalon R, Martinez J, Hamel D. Does living in rural areas make a difference for health in Quebec?. Health \& place. 2006 Dec 1; 12(4):421-35.

https://doi.org/10.1016/j.healthplace.2005.04.002

13. Małecka B. Long-term consequences of endocardial leads present in cardiovascular system. Modern pacemakers: Present and future. InTech, Rijeka, Croatia. 2011 Feb 14; 351-66. https://doi.org/10.5772/13733

14. Homburg PJ, Rozie S, van Gils MJ, Jansen T, de Weert TT, Dippel DW, van der Lugt A. Atherosclerotic plaque ulceration in the symptomatic internal carotid artery is associated with nonlacunar ischemic stroke. Stroke. 2010 Jun 1; 41(6):1151-6. https://doi.org/10.1161/STROKEAHA.109.576256

15. Lavallée PC, Labreuche J, Faille D, Huisse MG, Nicaise-Roland P, Dehoux M, Gongora-Rivera F, Jaramillo A, Brenner D, Deplanque D, Klein IF. Circulating markers of endothelial dysfunction and platelet activation in patients with severe symptomatic cerebral small vessel disease. Cerebrovascular diseases. 2013; 36(2):1318. https://doi.org/10.1159/000353671

16. Sanderson TH, Reynolds CA, Kumar R, Przyklenk K, Hüttemann M. Molecular mechanisms of ischemia-reperfusion injury in brain: pivotal role of the mitochondrial membrane potential in reactive oxygen species generation. Molecular neurobiology. 2013 Feb; 47(1):9-23. https://doi.org/10.1007/s12035-0128344-z

17. Seike K, Koda K, Saito N, Oda K, Kosugi C, Shimizu K, Miyazaki M. Laser Doppler assessment of the influence of division at the root of the inferior mesenteric artery on anastomotic blood flow in rectosigmoid cancer surgery. International journal of colorectal disease. 2007 Jun; 22(6):689-97.

https://doi.org/10.1007/s00384-006-0221-7

18. White RE, Gerrity R, Barman SA, Han G. Estrogen and oxidative stress: A novel mechanism that may increase the risk for cardiovascular disease in women. Steroids. 2010 Nov 1; 75(11):788-93. https://doi.org/10.1016/j.steroids.2009.12.007

19. Vincent MJ, Allen B, Palacios OM, Haber LT, Maki KC. Metaregression analysis of the effects of dietary cholesterol intake on LDL and HDL cholesterol. The American journal of clinical nutrition. 2019 Jan 1; 109(1):7-16. https://doi.org/10.1093/ajcn/nqy273

20. Della-Morte D, Guadagni F, Palmirotta R, Testa G, Caso V, Paciaroni M, Abete P, Rengo F, Ferroni P, Sacco RL, Rundek T. Genetics of ischemic stroke, stroke-related risk factors, stroke precursors and treatments. Pharmacogenomics. 2012 Apr; 13(5):595-613. https://doi.org/10.2217/pgs.12.14

21. Castelli WP. Lipids, risk factors and ischaemic heart disease. Atherosclerosis. 1996 Jul 1; 124:S1-9. https://doi.org/10.1016/0021-9150(96)05851-0

22. Andaryani NW, Nuartha AA, Adnyana IM. Rasio kadar trigliserida-kolesterol HDL serum tinggi meningkatkan keparahan klinis penderita stroke iskemik akut. Medicina. 2017; 48(3):211-5. https://doi.org/10.15562/medicina.v48i3.161

23. Pratiwi LN, Andina M. Differences in Triglyceride Levels and Total Cholesterol Levels in Patients with New Ischemic Stroke and Recurrents at the General Hospital of Haji Medan, North 
Sumatra Province 2015-2016. Anatomica Medical Journal AMJ. 2018 May 30; 1(2):58-67.

24. Nakajima K, Nakano T, Tanaka A. The oxidative modification hypothesis of atherosclerosis: the comparison of atherogenic effects on oxidized LDL and remnant lipoproteins in plasma. Clinica Chimica Acta. 2006 May 1; 367(1-2):36-47. https://doi.org/10.1016/j.cca.2005.12.013

25. Bays HE, Ballantyne CM, Kastelein JJ, Isaacsohn JL, Braeckman RA, Soni PN. Eicosapentaenoic acid ethyl ester (AMR101) therapy in patients with very high triglyceride levels (from the Multi-center, plAcebo-controlled, Randomized, double-blind, 12-week study with an open-label Extension [MARINE] trial). The American journal of cardiology. 2011 Sep 1; 108(5):682-90. https://doi.org/10.1016/j.amjcard.2011.04.015

26. Mandala Z. Comparison of Blood Lipid Profile Levels on Ischemic Stroke and Hemoragic Stroke In Dr. H. Abdoel Moeloek Bandar Lampung, 2014. Jurnal Medika Malahayati. 2015; 2(2):86-90.

27. Nadeak B, Iriani UE, Naibaho L, Sormin E, Juwita CP. Building Employees' Mental Health: The Correlation between Transactional Leadership and Training Program with Employees' Work Motivation at XWJ Factory. Indian Journal of Public Health Research \& Development. 2019; 10(6):1373-9. https://doi.org/10.5958/0976-5506.2019.01489.X

28. Amaliah, R., Mokhtar, S., Namirah, H. A., Rachman, M. E., \& Syamsu, R. F. (2020). Characteristics of Lipid Profile Levels in Ischemic Stroke Patients at Ibnu Sina Makassar's Hospital In 2017. Wal'afiat Hospital Journal, 1(1).

29. Amaliah R, Mokhtar S, Namirah HA, Rachman ME, Syamsu RF. Characteristics of Lipid Profile Levels in Ischemic Stroke
Patients at Ibnu Sina Makassar's Hospital In 2017. Wal'afiat Hospital Journal. 2020 May 21; 1(1).

30. Hurtubise J, McLellan K, Durr K, Onasanya O, Nwabuko D, Ndisang JF. The different facets of dyslipidemia and hypertension in atherosclerosis. Current atherosclerosis reports. 2016 Dec; 18(12):1-2. https://doi.org/10.1007/s11883-0160632-z

31. Ho ML, Rojas R, Eisenberg RL. Cerebral edema. American Journal of Roentgenology. 2012 Sep; 199(3): W258-73. https://doi.org/10.2214/AJR.11.8081

32. Nadeak B, Naibaho L. The Description of medical students' interest and achievement on anatomy at faculty of medicine Universitas Kristen Indonesia. International Journal of Sciences: Basic and Applied Research (IJSBAR). 2018; 39(1):121-33.

33. Saputri, A. I., \& Maulina, M. Relationship of Lipid Profile with Long Care of Ischemic Stroke Patients in The Cut Meutia Public Hospital Agency, North Aceh District. Averrous: Jurnal Kedokteran dan Kesehatan Malikussaleh, 2018; 2(1):90-102. https://doi.org/10.29103/averrous.v2i1.428

34. Saputri AI, Maulina M. Relationship of Lipid Profile ith Long Care of Ischemic Stroke Patients in The Cut Meutia Public Hospitaw, North Aceh District. Averrous: Jurnal Kedokteran dan Kesehatan Malikussaleh. 2018 Feb 16; 2(1):90-102. https://doi.org/10.29103/averrous.v2i1.428

35. Welty FK. How do elevated triglycerides and low HDLcholesterol affect inflammation and atherothrombosis?. Current cardiology reports. 2013 Sep 1; 15(9): 400. https://doi.org/10.1007/s11886-013-0400-4 